\title{
The Composition Analysis of Maca (Lepidium meyenii Walp.) from Xinjiang and Its Antifatigue Activity
}

\author{
Jieying Li, ${ }^{1,2}$ Longfei Chen, ${ }^{2}$ Jinwei Li, ${ }^{1,2}$ Zhenhua Duan, ${ }^{3}$ Song $\mathrm{Zhu}^{2}$ and Liuping Fan ${ }^{1,2}$ \\ ${ }^{1}$ State Key Laboratory of Dairy Biotechnology, Technology Center, Bright Dairy \& Food Co. Ltd., Shanghai 200436, China \\ ${ }^{2}$ School of Food Science and Technology, Jiangnan University, Wuxi 214122, China \\ ${ }^{3}$ Institute of Food Research, Hezhou University, Guangxi 542899, China
}

Correspondence should be addressed to Zhenhua Duan; dzh65@126.com and Liuping Fan; fanliuping@jiangnan.edu.cn

Received 30 May 2017; Revised 11 October 2017; Accepted 16 October 2017; Published 16 November 2017

Academic Editor: Hui-Min D. Wang

Copyright (C) 2017 Jieying Li et al. This is an open access article distributed under the Creative Commons Attribution License, which permits unrestricted use, distribution, and reproduction in any medium, provided the original work is properly cited.

\begin{abstract}
Environment would affect the nutritional composition of maca, especially its secondary metabolite. The chemical compositions and function of Xinjiang maca were not very clear. The chemical compositions and bioactivity of Xinjiang maca were determined. A mouse model was also used to evaluate the antifatigue activity of Xinjiang maca as a forced swimming test was performed and certain biochemical parameters related were estimated. The results show that the Xinjiang maca is rich in protein content and amino acids, especially branched chain amino acids such as Valine and Isoleucine related to the effect of antifatigue. It also has considerable minerals ions such as $\mathrm{Ca}$ and $\mathrm{Mg}$. Besides, bioactive ingredients such as maca amide, glucosinolate, and alkaloid of Xinjiang maca are similar to those of maca from other areas, which qualify the biological value of Xinjiang maca. The results of mice model suggest that maca has a dose-dependent antifatigue activity by decreasing blood lactic acid, as well as increasing liver glycogen content and the forced swimming time.
\end{abstract}

\section{Introduction}

Maca (Lepidium meyenii Walp.), a biennial herbaceous plant of the family brassicae, which is cultivated mainly in the central Andes of Peru at elevations of 3500-4500 $\mathrm{m}$ above sea level, has been used as both a food and a traditional medicine in the region for over 2000 years [1]. Domestic and foreign experts researched on the nutritional compositions and secondary metabolites of maca, finding that it not only contains rich protein, amino acids, fat, and minerals ion [2] but also contains a variety of secondary metabolites: maca ene, alkaloid (including maca amide), glucosinolate, and other components [3-5]. These secondary metabolites are considered closely related to the health effects of maca. Recent research shows that the logical ability of maca includes improving fertility, improving sexual performance, antiproliferative function, improving growth rate, antipostmenopausal osteoporosis, and ability in vitality and stress tolerance [6]. Most studies have been conducted to examine its biological activity on enhancing sexual performance or fertility. Only few reports show the antifatigue effect of maca powder [7] or maca extract [8]. Maca mainly grows at a cold but humid climate since its hardy, strong adaptability, so it is suitable to plant it in the high altitude region for $2700-3200 \mathrm{~m}$ above sea level in some areas of western China [9]. In 2004, Yunnan Huize introduced maca from the United States and the cultivation experiment was a success [10]. In China, maca is currently mainly cultivated in the Yunnan region, where its cultivation has formed a certain scale [11]. In addition to Yunnan, Pamirs in China Xinjiang is also suitable to cultivate maca for its geographical location and climate where maca has also been introduced recently. However, only a few reports were carried out to analyze the chemical composition and biology activity of yellow maca cultivated at Pamirs in China Xinjiang [12]. Its nutritional value and quality evaluation are not clear and deserve further evaluation. In addition, those foods in which maca is the main raw material, such as maca candy and maca granules, are popular in the market. In recent years, the unique overall effect of maca has been widespread in the world of health food industry, especially after China introduced maca as a kind of new resource food in 2011 [13]. Recently, many kinds of health 
products with maca as the main raw material on the market rapidly expand and have been getting more and more concerns. However, their declared antifatigue effect has not been confirmed by actual data and it is difficult to guarantee their quality.

Only a few researches related to the chemical composition and biology activity of Xinjiang maca although it has been planted widely in Xinjiang. In this paper, the contents of essential nutritional compositions of maca cultivated in Xinjiang are investigated. The contents of basic chemical compositions of water content, oil content, protein content, amino acid content, and mineral content were analyzed. Besides, the biological activities of some secondary metabolites were investigated, such as alkaloids, maca amide, and glucosinolates. The quality of Xinjiang maca can be valued in the level of composition ingredients by comparison with the data from other reports about the compositions of maca. Animal models were also made to test the antifatigue effect of Xinjiang maca, in order to provide theoretical support for further development of health care products made of Xinjiang maca.

\section{Materials and Methods}

2.1. Materials. The dried yellow maca root was collected from Pamir in Xinjiang Province at altitude of $3000 \mathrm{~m}$ provided by Tangshiyi Biotechnology Co., Ltd. The dried maca was grounded into fine powder $(75 \mu \mathrm{m})$ using a crusher. The roots were stored in polyethylene bags and frozen at $-20^{\circ} \mathrm{C}$ until their use.

2.2. Chemicals and Instruments. Reagents used for chromatography were of HPLC grade (Fisher, Pittsburgh, USA). Other reagents used were of analytical grade. A crusher (Ningbo Shunhui Electric Appliance Co. Ltd., Zhejiang, China) was used for crushing the maca tubers to powders. A UV 2600 spectrophotometer was used in all absorbance measurements (Techcomp Ltd., Shanghai, China). A fridge (Haier Co. Ltd., Shandong, China) was used for storing the samples until tested. An H1850 Centrifuge (Xiangyi Centrifuge Instrument Co., LTD., China) was used for centrifugation.

\subsection{Analysis Method of Compositions}

2.3.1. Analysis Method of Chemical Compositions. Moisture content was determined by the Association of Official Analytical Chemists 925.10 method [14]. The crude protein content was established in a Kjeldahl apparatus, following the AOAC 920.87 method [14]. The factor $N \times 6.25$ was used to convert nitrogen into crude protein. The crude fat content was determined by an SOX 406 automatic fat analyzer (Hanon Instruments, Shandong, China). Petroleum ether was used as solvent and the operating temperature was $70^{\circ} \mathrm{C}$. The crude ash content was determined by the AOAC 923.03 method [14]. Amino acids were determined using a Mikrotechna AAA 881 automatic amino acid analyzer according to the method described by Moore and Stein [15]. Hydrolysis of the samples was performed in the presence of $6 \mathrm{M} \mathrm{HCl}$ at $110^{\circ} \mathrm{C}$ for $24 \mathrm{~h}$ under nitrogen atmosphere. To estimate the content of minerals ion, maca samples were digested by concentrated nitric acid and perchloric acid $(4: 1, \mathrm{v} / \mathrm{v})$. Minerals ion $(\mathrm{K}, \mathrm{Na}$, $\mathrm{Mg}, \mathrm{Ca}, \mathrm{Zn}, \mathrm{Fe}, \mathrm{Cu}$, and $\mathrm{Mn}$ ) were measured by using an atomic absorption spectrophotometer (Shimadzu Instruments, Inc., AAF-7000F, Kyoto, Japan) following the recommendations of the Association of Official Analytical Chemists [14].

2.3.2. Analysis Method of Bioactive Ingredients. The content of total alkaloids in maca was determined by acidic dye colorimetry as described by Gan et al. [16]. Bromothymol blue was used for chromogenic agent and nuciferine was used as standard to draft the standard curve. The content of maca amide is determined by the method of HPLC-MS [17]. Nbenzyl hexadecanamide was used as standard. The content of glucosinolates was estimated by the HPLC-MS method [18]. Benzyl glucosinolate was used as standard.

\subsection{Antifatigue Effects In Vivo of Maca}

2.4.1. Reagents and Kits. The diagnostic kits for blood lactic acid, tissue glycogen, and serum urea nitrogen were purchased from Jiancheng Bioengineering Institute (Nanjing, China). Other commercial chemicals used in the experiments were of analytical grade and were purchased from Guoyao Chemical Reagent Factory (Shanghai, China).

2.4.2. Experiment Animals. 160 male Kunming mice, weighing $18-22 \mathrm{~g}$ at the beginning of the study, were purchased from Shanghai SLAC Laboratory Animal Co., Ltd. (Shanghai, China), License Number: SCXK (Shanghai) 2012-0002, certificate number: 2013001805390. They were fed under controlled environmental conditions of temperature $(22 \pm$ $2{ }^{\circ} \mathrm{C}$ ) and a 12 -h light/dark cycle and maintained on a standard rodent diet and tap water unless otherwise stated. All animals received professional humane care in compliance with the guidelines of the Experimental Animal Management and Animal Welfare Ethics Committee of Jiangnan University (Wuxi, China). The number of animal experimental ethical inspection is JN Number 20140417-0529(30).

2.4.3. Experiment Design. After one week of adaptation, the mice were randomly divided into four groups (40 mice in each group) as follows: (i) control (C) group: the mice were allowed free access to a standard rodent diet and treated with distilled water; (ii) low-dose Maca-treated (LMT) group: the mice were allowed free access to a standard rodent diet and treated with $40 \mathrm{mg} / \mathrm{kg}$.bw of maca; the maca tuber powder was dissolved in distilled water; (iii) moderate-dose Macatreated (MMT) group: the mice were allowed free access to a standard rodent diet and treated with $400 \mathrm{mg} / \mathrm{kg}$.bw of maca; (iv) high-dose Maca-treated (HMT) group: the mice were allowed free access to a standard rodent diet and treated with $1200 \mathrm{mg} / \mathrm{kg}$ body weight of maca. All treatment groups were administrated with the same volume at $0.2 \mathrm{~mL} / 10 \mathrm{~g} . \mathrm{bw} \cdot$ day by gavage using a feeding needle, once a day for 30 consecutive days. All mice were provided with free access to standard rodent pellet food, which contains crude protein $(18 \%)$, crude fat (4\%), crude fiber (5.0\%), Ca (1-1.8\%), P (0.6-1.2\%), 
moisture (10\%), and ash (8\%). The body weights of mice were measured weekly.

2.4.4. Forced Swimming Test. The forced swimming test was analyzed according to the method describe by Zhang et al. [19] with some modification. After the last treatment, 10 mice of each dose group were used for the forced swimming test. The 40 mice were allowed to rest for $30 \mathrm{~min}$ and then weighted and loaded with a tin wire (5\% of body weight) attached to the tail. The forced swimming capacity of mice was carried out in an acrylic plastic pool $(50 \mathrm{~cm} \times 50 \mathrm{~cm}$ $\times 40 \mathrm{~cm}$ ) with $30-\mathrm{cm}$-deep water at $25 \pm 0.5^{\circ} \mathrm{C}$. The water was stirred to keep the mice limbs moving. The mice were determined to be exhausted when they failed to return to the surface of water to breathe within a 7-s period; then the forced swimming time was immediately recorded.

2.4.5. Blood Lactic Acid Assay. Blood lactic acid was analyzed according to the method describe by Zhang et al. [19] with some modification. After the last treatment, 10 mice of each dose group were used for the blood lactic acid assay. The mice were allowed to rest for $30 \mathrm{~min}$, and then forced to swim without loads in the swimming pool as described in forced swimming test for $10 \mathrm{~min}$ while the water temperature was changed to $30 \pm 0.5^{\circ} \mathrm{C}$. Fifty microliters of blood sample was collected by inner canthus bleeding method before, immediately after, and $20 \mathrm{~min}$ resting after swimming, respectively. Blood samples of the mice were collected in heparinized tubes. The concentration of blood lactic acid was determined by the kits purchased from Nanjing Jiancheng Bioengineering Institute (Nanjing, China). The accumulation of blood lactic acid (the area of blood lactic acid under the curve) was calculated according to technical standards for testing and assessment of health food [20] using the following equation:

The accumulation of blood lactic acid

$$
=\frac{1}{2}(a+b) \times 10+\frac{1}{2}(b+c) \times 20 .
$$

In the equation, $a$ is the blood lactic acid concentration of mice before swimming; $b$ is the blood lactic acid concentration of mice immediately after swimming; $c$ is the blood lactic acid concentration of mice $20 \mathrm{~min}$ (resting) after swimming.

2.4.6. Serum Urea Nitrogen Analysis. After the last treatment, 10 mice of each dose group were used for the serum urea nitrogen analysis. After swimming for $90 \mathrm{~min}$ without loads (as described in blood lactic acid test), the blood samples were collected through removing the eyeball and then centrifuged at $3500 \times \mathrm{g}, 4^{\circ} \mathrm{C}$ for $15 \mathrm{~min}$ before analysis. The concentration of serum urea nitrogen was determined by the serum urea nitrogen kits.

2.4.7. Liver Glycogen Analysis. After the last treatment, the other 40 mice were allowed to rest for $30 \mathrm{~min}$ and then sacrificed by decapitation under anesthesia with sodium pentobarbital $(40 \mathrm{mg} / \mathrm{kg} . \mathrm{bw}, \mathrm{ip})$ to collect livers. The livers were washed with $0.9 \%$ saline and blotted by a filter paper. The liver sample $(\sim 100 \mathrm{mg})$ was accurately weighted. The content of liver glycogen was determined according to the recommended procedures provided by the kits purchased from Nanjing Jiancheng Bioengineering Institute (Nanjing, China).

2.5. Data Analysis. The tests in this paper were duplicated for each sample and mean values of the duplicated tests are presented. Comparisons were carried out on software of SPSS for Windows (version 19.0, SPSS Inc. 2015). All animal experimental data were expressed as the mean \pm SD. The data were subjected to one-way analysis of variance. $P<0.05$ was considered to be statistically significant.

\section{Results and Discussion}

\subsection{Compositions of Xinjiang Maca}

3.1.1. Chemical Compositions. It is showing in Table 1 that the water content of the maca cultivated in Xinjiang is 7.01\%, which is slightly lower than the data reported by Dini et al. (10.40\%) (1997), as well as Yang et al. (10.40\%) [21], while it is close to that reported by Yu and Jin (7.64\%) [22]. Protein is the most important nutrient for human since it is related to organisms running and life activities, so that protein content is an important indicator of the nutritional value of foods. As it shows from Table 1, the protein content of yellow maca cultivated in Xinjiang is $13.42 \%$, which is higher than protein content of $10.2 \%$ reported by Dini et al. [2], 9.1\% reported by Yang et al. [21], and 8.87\% reported by Yu et al. (2004). It means that Xinjiang maca is an abundant resource of nutrition as a new kind of introduced food. The lipid content of $1.42 \%$ is lower when compared to the results of $2.2 \%$ by Dini et al. [2] and 2.0\% by Yu et al. (2004), but it is close to result of $1.38 \%$ reported by Yang et al. [21]. This variation may be attributed to the planting environment. The ash content of $3.41 \%$ in our report is similar to $3.08 \%$ reported by $\mathrm{Du}$ et al. [23].

3.1.2. Amino Acid Composition. The amino acid composition (Table 2) shows that Xinjiang maca has a high content of essential amino acids, reaching $27.2 \%$. Compared with the essential amino acid pattern of FAO-WHO in 1973 [24], the contents of methionine, phenylalanine, and leucine are, respectively, $8.5 \mathrm{mg} / \mathrm{g}$ protein, $31.9 \mathrm{mg} / \mathrm{g}$ protein, and $46.4 \mathrm{mg} / \mathrm{g}$ protein, which are lower than essential amino acid pattern. The contents of Threonine, Valine, Isoleucine, and Lysine are, respectively, $32.7 \mathrm{mg} / \mathrm{g}$ protein, $65.0 \mathrm{mg} / \mathrm{g}$ protein, $36.6 \mathrm{mg} / \mathrm{g}$ protein, and $50.4 \mathrm{mg} / \mathrm{g}$ protein, which are close to those in the pattern. The Valine content of $65.0 \mathrm{mg} / \mathrm{g}$ protein is much higher than that of $50 \mathrm{mg} / \mathrm{g}$ protein in the pattern. Valine is closely connected with the antifatigue activity of maca. Besides, Isoleucine and Leucine can also contribute to the antifatigue function of maca. As a result, maca cultivated in Xinjiang shows an excellent profile, confirmed by the high content in essential amino acids.

3.1.3. Mineral Composition. Mineral compositions of yellow maca cultivated in Xinjiang are shown in Table 3. The three elements including $\mathrm{Ca}, \mathrm{Mg}$, and $\mathrm{Zn}$ are closely related to the 
TABLE 1: Compositions of yellow maca cultivated in Xinjiang.

\begin{tabular}{lccccccc}
\hline Compositions & $\begin{array}{c}\text { Water } \\
\text { content } / \%\end{array}$ & $\begin{array}{c}\text { Protein } \\
\text { content } / \%\end{array}$ & $\begin{array}{c}\text { Oil } \\
\text { content } / \%\end{array}$ & Ash content/\% & $\begin{array}{c}\text { Maca amide } \\
(\mathrm{mg} / \mathrm{g} \text { maca })\end{array}$ & $\begin{array}{c}\text { Glucosinolate } \\
(\mathrm{mg} / \mathrm{g} \text { maca })\end{array}$ & $\begin{array}{c}\text { Alkaloid } \\
(\mathrm{mg} / \mathrm{g} \text { maca })\end{array}$ \\
\hline Maca & $7.01 \pm 0.04$ & $13.42 \pm 0.57$ & $1.42 \pm 0.16$ & $3.41 \pm 0.02$ & $0.17 \pm 0.01$ & $1.24 \pm 0.04$ & $0.20 \pm 0.05$ \\
\hline
\end{tabular}

Data in this table are all expressed by wet basis content.

TABle 2: Amino acid composition of yellow maca cultivated in Xinjiang.

\begin{tabular}{|c|c|c|c|}
\hline Amino acids & $\begin{array}{c}\text { Content } \\
\mathrm{mg} / \mathrm{g} \text { protein }\end{array}$ & $\begin{array}{l}\text { Essential amino } \\
\text { acid pattern }\end{array}$ & $\begin{array}{l}\text { Chemical } \\
\text { score }\end{array}$ \\
\hline \multicolumn{4}{|c|}{ Essential amino acid } \\
\hline Threonine* & 32.7 & 40 & 82 \\
\hline Valine* & 65.0 & 50 & 130 \\
\hline Methionine* & 8.5 & 35 & 24 \\
\hline Phenylalanine $e^{*}$ & 31.9 & 60 & 53 \\
\hline Isoleucine $^{*}$ & 36.6 & 40 & 92 \\
\hline Leucine $^{*}$ & 46.4 & 70 & 66 \\
\hline Lysine ${ }^{*}$ & 50.4 & 55 & 92 \\
\hline \multicolumn{4}{|c|}{ Nonessential amino acid contents } \\
\hline Aspartate & & 82.8 & \\
\hline Glutamate & & 138.9 & \\
\hline Serine & & 25.4 & \\
\hline Histidine & & 27.5 & \\
\hline Glycine & & 43.1 & \\
\hline Arginine & & 202.3 & \\
\hline Alanine & & 39.4 & \\
\hline Tyrosine & & 22.8 & \\
\hline Cysteine & & 2.5 & \\
\hline Proline & & 0.5 & \\
\hline
\end{tabular}

(a) Amino acid with “*” means one of the essential amino acids; (b) Chemical score $=100 *$ (per gram of the amino acid contents in detected protein/per gram the amino acid contents in the essential amino acid pattern).

antifatigue activity of maca. The Xinjiang maca is especially rich in the content of $\mathrm{Mg}, \mathrm{Ca}$, and $\mathrm{K}$. Although the content of $\mathrm{Cu}$ is slightly lower and the content of $\mathrm{Ca}$ is higher, the other mineral contents of the Xinjiang maca are found to be in consistency with the results of earlier investigation by Dini et al. [2].

3.1.4. Biological Active Ingredients. Alkaloid is one of the most important bioactive components and it is related to many healthy effects of maca. From Table 1, we can find that the content of alkaloid in Xinjiang maca is $0.20 \%$. This result is similar to the data $0.22 \%$ reported by Gan et al. [16]. As the unique alkaloid only found in maca, maca amide was reported to have influence on increasing libido [25]. The content of maca amide is $0.17 \mathrm{mg} / \mathrm{g}$ maca $(0.0017 \%)$, which is in accord with the range of $0.0016 \%-0.013 \%$ in other reports [26]. Glucosinolates are secondary metabolites with negative ion hydrophilic which contain sulphur and nitrogen in plant.
There are changeable side chains $(\mathrm{R})$ and a sulpho $\beta$-Dglucofuranoses in them [27]. The decomposition products of them and themselves were considered to have lots of biological activity, such as the ability to combat pathogens and cancer. The content of glucosinolate was shown in Table 1 . The benzyl glucosinolate content of Xinjiang maca is $1.24 \mathrm{mg} / \mathrm{g}$ maca, which also means that the proportion of glucosinolate is $0.124 \%$ in maca. This is lower than the result of $0.2 \%$ reported by Li et al. [5].

\subsection{Mice Experimental Results}

3.2.1. Effect of Xinjiang Maca on Forced Swimming Time. Fatigue is one of the most frequent physiological reactions. Tan et al. [28] have described the complex mechanism of fatigue as follows: it is caused by the depletion of energy sources, including decrease in glycemic levels and liver glycogen consumption. The side effects of fatigue include the accumulation of blood lactic acid, the disorder of internal environment, and metabolic control disorders of nervous system [28]. In our report, the forced swimming test was performed and certain biochemical parameters related were estimated.

The forced swimming test is a common experimental exercise model to evaluate the antifatigue activity [29]. The maximum swimming time is directly related to the ability of fatigue, so prolonged swimming times in forced swimming test indicate an increasing ability of antifatigue [30].

The effects of Xinjiang maca on forced swimming time are shown in Figure 1. As we can see from Figure 1, forced swimming times of mice in MMT and HMT groups are significantly longer $(P<0.05)$ than that in control group and increase by $54.3 \%$ and $77.3 \%$, respectively. Forced swimming time in LMT group is $17.7 \%$ longer than that in the control group but the difference is not significant. This may be attributed to the lower dose of LHT group, which is only $10 \%$ of the dose in MMT and 3.33\% of that in HMT, respectively. Wen et al. [31] found that the forced swimming time of mice with $5.0 \mathrm{~g} / \mathrm{kg}$ BW Yunnan maca significantly extended and reached 324 sec compared with the control, which was $211 \mathrm{sec}$. These results indicated that Xinjiang maca has significant antifatigue activity when the dose is enough and is capable of elevating the exercise tolerance in mice.

\subsubsection{Effect of Xinjiang Maca on Blood Lactic Acid Content.} During intense exercises, the muscle produces a considerable amount of lactic acid when it obtains sufficient energy from anaerobic glycolysis, and the increased concentration of lactic acid brings about a reduction in the $\mathrm{pH}$ value in muscle tissue and blood, which could induce various biochemical and physiological side effects and lead to fatigue [32]. Therefore, 
TABLE 3: Mineral ion composition of yellow maca cultivated in Xinjiang (mg/kg).

\begin{tabular}{lcccccccc}
\hline Mineral ion & $\mathrm{Zn}$ & $\mathrm{Fe}$ & $\mathrm{Cu}$ & $\mathrm{Mn}$ & $\mathrm{K}$ & $\mathrm{Na}$ & $\mathrm{Mg}$ & $\mathrm{Ca}$ \\
\hline Content & $30.7 \pm 1.3$ & $82.4 \pm 0.8$ & $5.9 \pm 0.6$ & $11.2 \pm 0.6$ & $11700.0 \pm 141.4$ & $188.0 \pm 24.9$ & $847.5 \pm 15.3$ & $13700.0 \pm 282.8$ \\
\hline
\end{tabular}

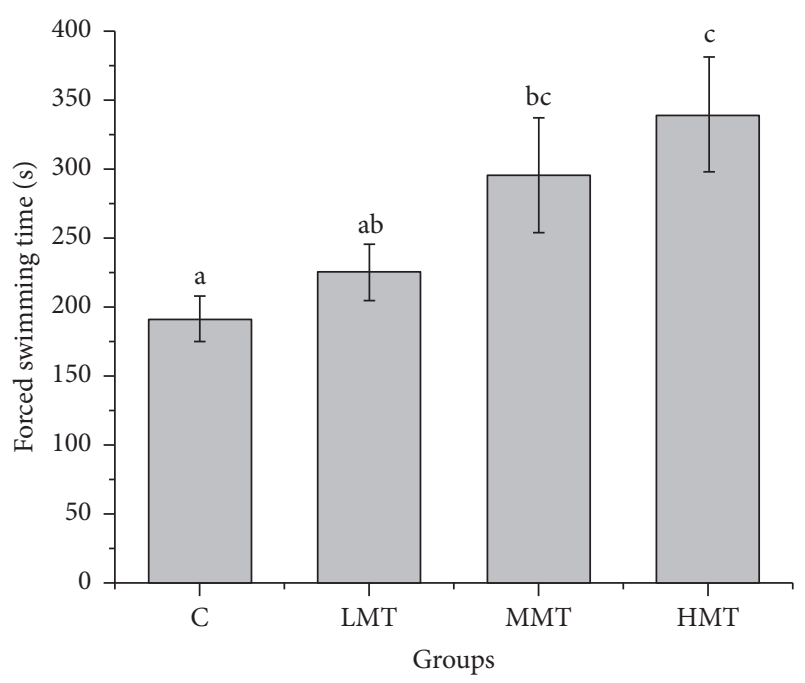

FIGURE 1: Effect of Xinjiang maca on forced swimming time (C, control; LMT, low-dose maca-treated group; MMT, medium-dose maca-treated group; HMT, high-dose maca-treated group. Each value represents the mean $\pm \mathrm{SD}(n=10)$. Different letters indicate significant differences among groups $(P<0.05))$.

blood lactic acid content is a sensitive index of fatigue status. The accumulation of blood lactic acid content can be an integrated indicator for investigating the changes of blood lactic acid content.

The effect of Xinjiang maca on blood lactic acid content is shown in Figure 2. We can find that after a 10-min swimming and 20-min rest, the accumulations in MMT and HMT groups were significantly lower than that in the control group $(P<0.05)$, decreased by $23.9 \%$ and $28.2 \%$, respectively. This result was similar to those of Zhang et al. [33] and Gao et al. [34], which used Yunnan maca and Peru maca, respectively. The accumulation of blood lactic acid content in LMT group is also lower than the control group, but it is not significant. These results indicate that Xinjiang maca effectively delays the increase in blood lactic acid content, reduced the catabolism of protein for energy, and increased the adaptive capacity to exercise load. However, the dose of Xinjiang maca should be taken into consideration to reach the antifatigue activity.

\subsubsection{Effect of Xinjiang Maca on Serum Urea Nitrogen} Content. Urea is formed in the liver as the end product of protein metabolism. Protein and amino acids have a stronger catabolic metabolism when the body cannot acquire enough energy produced by carbohydrates and fat catabolic metabolism after an intense exercise, during which urea nitrogen increases [35]. Thus, serum urea nitrogen content is another sensitive index of fatigue status.

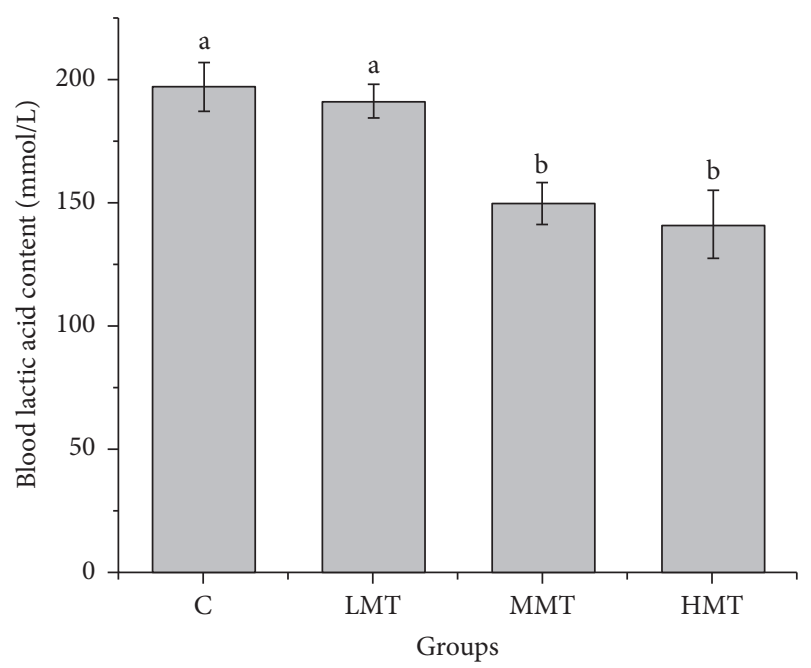

Figure 2: Effect of Xinjiang maca on blood lactic content (C, control; LMT, low-dose maca-treated group; MMT, medium-dose maca-treated group; HMT, high-dose maca-treated group. Each value represents the mean $\pm \mathrm{SD}(n=10)$. Different letters indicate significant differences among groups $(P<0.05))$.

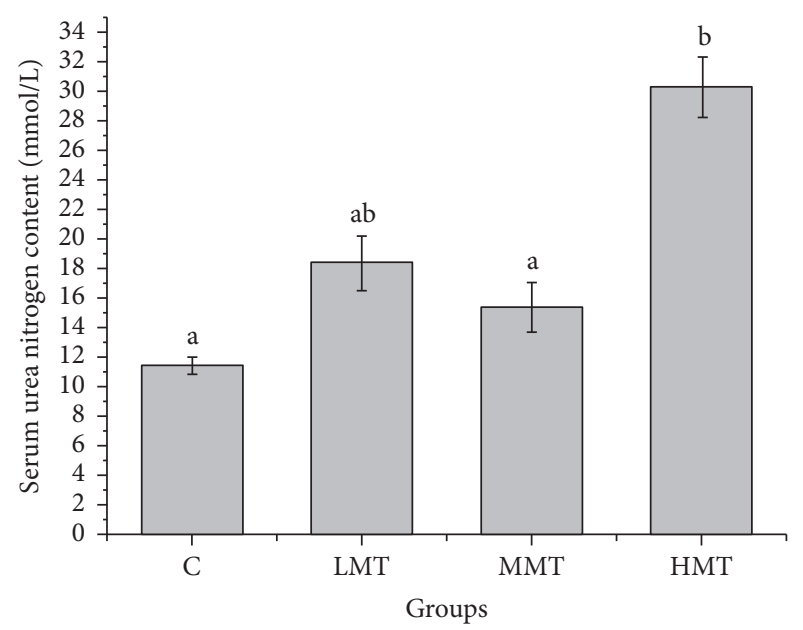

FIGURE 3: Effect of Xinjiang maca on serum urea nitrogen content (C, control; LMT, low-dose maca-treated group; MMT, mediumdose maca-treated group; HMT, high-dose maca-treated group. Each value represents the mean \pm SD $(n=10)$. Different letters indicate significant differences among groups $(P<0.05))$.

As shown by Figure 3, the serum urea nitrogen contents of LMT and MMT groups are not significantly higher than that of control group. This results show that LMT and MMT group can not significantly increase the serum urea nitrogen content. The serum urea nitrogen content of HMT group 


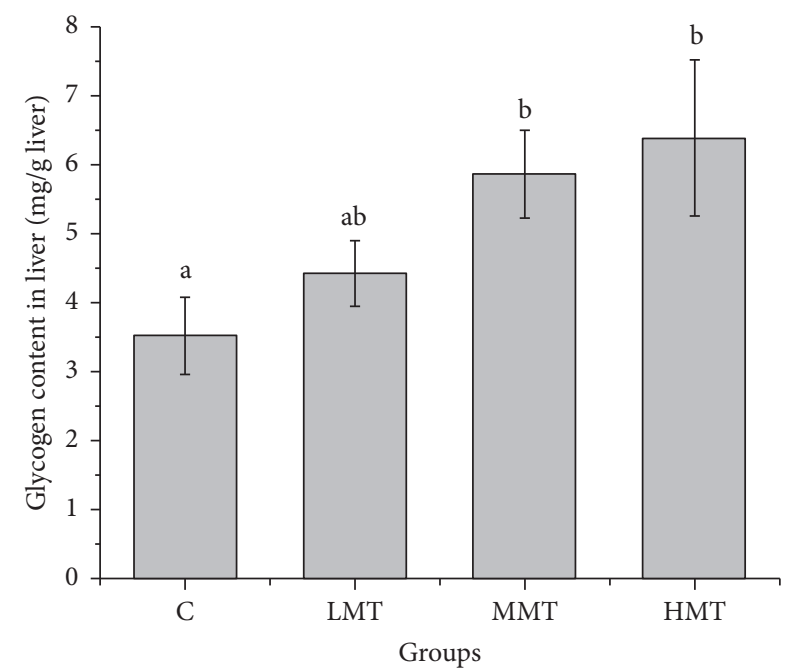

FIGURE 4: Effect of Xinjiang maca on glycogen content in liver (C, control; LMT, low-dose maca-treated group; MMT, medium-dose maca-treated group; HMT, high-dose maca-treated group. Each value represents the mean $\pm \mathrm{SD}(n=10)$. Different letters indicate significant differences among groups $(P<0.05))$.

is significantly higher than that of the control group, which indicates that too much intake of maca may increase the burden of protein metabolism of body so that the serum urea nitrogen content of the dealing group was higher than the control group. As a consequence, the dose of maca for $1200 \mathrm{mg} / \mathrm{kg}$ bw in HMT group can do harm to the mice. However, Zhang et al. [33] found that Yunnan maca with the dosage of $0.4 \mathrm{~g} / \mathrm{kg} \mathrm{BW}$ and $1.2 \mathrm{~g} / \mathrm{kg}$ BW could significantly decrease the serum urea nitrogen content of mice compared with the control. Gao et al. [34] found that Peru maca during the experimental dosage has no obvious effect on the serum urea nitrogen content of mice compared with the control. The different results may be related to the different planting region and chemical composition.

3.2.4. Effect of Xinjiang Maca on Glycogen Content in Liver. Energy for exercise is derived initially from the breakdown of glycogen in muscle. After intense exercise, it may be depleted, and at later stages the energy will be derived from hepatic glycogen [36]. Therefore, the depletion of glycogen stores may be a significant factor in the development of fatigue.

The effects of Xinjiang maca on glycogen content in liver are shown in Figure 4. The liver glycogen content of MMT and HMT groups was significantly higher $(P<0.05)$ than that of control group, increased by $66.3 \%$ and $80.9 \%$, respectively. The glycogen content in liver in the LMT group is also lower, but not significantly $(P>0.05)$. These results indicated that Xinjiang maca may contribute to the activation of energy metabolism which could delay physical fatigue by increasing the storage of glycogen in liver. Also, as mentioned before, the intake of maca must reach a certain dose as to show the activity of antifatigue. Similarly, Zhang et al. [33] also found that Yunnan maca with the dosage of $0.4 \mathrm{~g} / \mathrm{kg}$
BW and $1.2 \mathrm{~g} / \mathrm{kg}$ BW could significantly increase the glycogen content in liver of mice compared with the control.

\section{Conclusions}

Xinjiang maca is rich in protein content and amino acids, especially branched chain amino acids such as Valine and Isoleucine related to the activity of antifatigue. It also has considerable minerals ion contents such as $\mathrm{Ca}$ and $\mathrm{Mg}$ which is related to antifatigue activity. Besides, biological active ingredient contents such as maca amide, glucosinolate, and alkaloid of Xinjiang maca are similar to those in maca from other areas, which indicates it can provide similar health benefits like maca from other areas. The results show that the dried powder of Xinjiang maca has a reasonable nutritional structure and is a kind of high value quality food. The results of mice experiment showed that intake of maca for $400 \mathrm{mg} / \mathrm{kg}$ bw and $1200 \mathrm{mg} / \mathrm{kg}$ bw can decrease blood lactic acid content as well as increase liver glycogen content and forced swimming time. However, maca intake of $1200 \mathrm{mg} / \mathrm{kg}$ bw can significantly increase the serum urea nitrogen content as to do harm to the body. So Xinjiang maca has a dose-dependent antifatigue effect by decreasing blood lactic acid as well as increasing liver glycogen content and forced swimming time. The intake dose of maca for $400 \mathrm{mg} / \mathrm{kg}$ bw can bring out significant antifatigue activity.

\section{Conflicts of Interest}

All authors declare that there are no conflicts of interest regarding the publication of this paper.

\section{Acknowledgments}

The authors acknowledge financial support of the Special Fund for Grain Research in the Public Interest (201513003-8), Agro-Scientific Research in the Public Interest (20130307301), China National Natural Science Foundation (31371812, 31401532), the Science and Technology Infrastructure Program of Jiangsu (BM2014051/004), the Open Project Program of State Key Laboratory of Dairy Biotechnology, Bright Dairy \& Food Co. Ltd. (SKLDB2016-003), The Six-Talent Peaks Project in Jiangsu Province, and QingLan Project, which has enabled us to carry out this study.

\section{References}

[1] H. E. Flores, T. S. Walker, R. L. Guimarães, H. P. Bais, and J. M. Vivanco, "Andean root and tuber crops: underground rainbows," HortScience, vol. 38, no. 2, pp. 161-167, 2003.

[2] A. Dini, G. Migliuolo, L. Rastrelli, P. Saturnino, and O. Schettino, "Chemical composition of Lepidium meyenii," Food Chemistry, vol. 49, no. 4, pp. 347-349, 1994.

[3] B. Cui, B. L. Zheng, K. He, and Q. Y. Zheng, "Imidazole alkaloids from Lepidium meyenii," Journal of Natural Products, vol. 66, no. 8, pp. 1101-1103, 2003.

[4] M. Ganzera, J. Zhao, I. Muhammad, and I. A. Khan, "Chemical profiling and standardization of Lepidium meyenii (Maca) by reversed phase high performance liquid chromatography," 
Chemical \& Pharmaceutical Bulletin, vol. 50, no. 7, pp. 988-991, 2002.

[5] G. Li, U. Ammermann, and C. F. Quirós, "Glucosinolate contents in maca (Lepidium peruvianum Chacón) seeds, sprouts, mature plants and several derived commercial products," Economic Botany, vol. 55, no. 2, pp. 255-262, 2001.

[6] Y. Wang, Y. Wang, B. McNeil, and L. M. Harvey, "Maca: An Andean crop with multi-pharmacological functions," Food Research International, vol. 40, no. 7, pp. 783-792, 2007.

[7] S. Shin, D. Park, J. H. Jeon, S. S. Joo, Y. B. Kim, and H. G. Kand, "Gelatinized and fermented powders of Lepidium meyenii (maca) improve physical stamina and epididymal sperm counts in male mice," Journal of Embryo Transfer, vol. 23, pp. 283-289, 2008.

[8] E. H. Choi, J. I. Kang, J. Y. Cho et al., "Supplementation of standardized lipid-soluble extract from maca (Lepidium meyenii) increases swimming endurance capacity in rats," Journal of Functional Foods, vol. 4, no. 2, pp. 568-573, 2012.

[9] R. F. Xie and X. Qu, "The introduction and cultivation techniques of Maca," Yunnan Agricultural Science, pp. 42-43, 2008.

[10] P. Q. Li, "Successful techniques of maca (a special herbal medicines introduced from US) cultivation in Yunnan Huize," Yunnan Rural Economy (China), pp. 94-95, 2007.

[11] H. Zheng, H. Zhang, J. Gan, L. F. Xu, Z. H. Zhang, and Y. Feng, "Introduction and cultivation of Peruvian ginseng (Lepidium meyenii Walp.) and its chemical utilization in China," Chemistry and Industry of Forest Products, pp. 255-259, 2009 (Chinese).

[12] W. W. Jin, Q. F. Wang, S. Li, L. M. Wang, and L. J. Yu, "GC-MS analysis of chemical components of essential oil from lepidium meyenii grown in xinjiang area," Food Science (China), vol. 30, pp. 241-245, 2009.

[13] Ministry of Public Health of China. (2011). Approval of introducing maca as a kind of a kind of new resource of food.

[14] AOAC (1990). Official Methods of Analysis of the Association of Official Analytical Chemists, 15th edn. Washington, DC: Association of Official Analytical Chemists.

[15] S. Moore and W. H. Stein, "Chromatographic determination of amino acids by the use of automatic recording equipment," in Methods in Enzymology, vol. 6, pp. 819-831, Academic Press, 1963.

[16] J. Gan, Y. Feng, H. E. Zhao, L. F. Xu, H. Zhang, and X. M. Chen, "Total alkaloids in maca (Lepidium meyenii) cultivated in Yunnan," Journal of Food Science, vol. 31, no. 24, pp. 415-419, 2010.

[17] Y. C. Zhu, B. H. Li, C. Y. Luo, C. H. Luo, and D. L. Huang, "Analysis of macaenes and macamides in maca plant by high performance liquid chromatograph-mass," Analytical Instruments, vol. 5, pp. 44-49, 2014 (Chinese).

[18] Z. Ai, A. F. Cheng, J. Y. Meng, H. Liu, L. J. Yu, and W. W. Jin, "Analysis of chemical components and content of glucosinolate from domestic Maca," in Food Science and Technology, vol. 4, pp. 182-186, 2012.

[19] W. Zhang, J. L. Cao, S. Z. Wu et al., "Anti-fatigue effect of yak milk powder in mouse model," Dairy Science Technology, vol. 95, pp. 245-255, 2015.

[20] Ministry of Public Health of China. (2003). Technical standards for testing and assessment of health food.

[21] J. M. Yang, Z. Wang, and Y. X. Yang, "Analysis and comparison of nutritional composition for dried maca," Chinese Journal of Food Hygiene, vol. 3, pp. 201-205, 2007.
[22] L. J. Yu and W. W. Jin, "Study on the nutritional components and the anti-fatigue effects of dry powder of maca (Lepidium meyenii)," Journal of Food Science, vol. 25, no. 2, pp. 164-166, 2004.

[23] P. Du, Y. Shan, H. Sun et al., "Nutritional compositions in fruit of maca (Lepidium meyenii Walp.) cultivated in Yunnan," Food Science (China), vol. 31, pp. 345-347, 2010.

[24] FAO/WHO. (1973). Energy and protein requirements. FAO nutrition meeting report series, 52-63.

[25] B. L. Zheng, K. He, C. H. Kim et al., "Effect of a lipidic extract from Lepidium meyenii on sexual behavior in mice and rats," Urology, vol. 55, no. 4, pp. 598-602, 2000.

[26] M. M. McCollom, J. R. Villinski, K. L. McPhail, L. E. Craker, and S. Gafner, "Analysis of macamides in samples of Maca (Lepidium meyenii) by HPLC-UV-MS/MS," Phytochemical Analysis, vol. 16, no. 6, pp. 463-469, 2005.

[27] C. Luo, H. Zhang, H. Zheng, J. Zhang, and J. Gan, “Optimization of glucosinolates extracted from maca(Lepidium meyenii) by combined ultrasonic and microwave extraction with response surface methodology," Advanced Materials Research, vol. 550553, pp. 1893-1899, 2012.

[28] W. Tan, K.-Q. Yu, Y.-Y. Liu et al., "Anti-fatigue activity of polysaccharides extract from Radix Rehmanniae Preparata," International Journal of Biological Macromolecules, vol. 50, no. 1, pp. 59-62, 2012.

[29] W. Tang, Y. Zhang, J. Gao, X. Ding, and S. Gao, “The antifatigue effect of $20(R)$-ginsenoside Rg3 in mice by intranasally administration," Biological \& Pharmaceutical Bulletin, vol. 31, no. 11, pp. 2024-2027, 2008.

[30] L. You, J. Ren, B. Yang, J. Regenstein, and M. Zhao, "Antifatigue activities of loach protein hydrolysates with different antioxidant activities," Journal of Agricultural and Food Chemistry, vol. 60, no. 50, pp. 12324-12331, 2012.

[31] J. L. Wen, F. Y. He, C. N. Han, Y. Li, R. Dai, and Q. Lin, “The effects of introduction Lepidium meyenii in Yunnan province on nonspecific immunity, fatigure and hypoxia function," Journal of Yunnan University of Traditional Chinese Medicine, vol. 35, no. 5, pp. 4-7, 2012 (Chinese).

[32] C. C. Huang, M. C. Hsu, W. C. Huang, H. R. Yang, and C. C. Hou, "Triterpenoid-Rich extract from antrodia camphorata improves physical fatigue and exercise performance in mice," Evidence-Based Complementary And Alternative Medicine, pp. $1-8,2012$.

[33] J. Zhang, H. Li, W. Zhou, H. Tang, and T. L. Zhang, "Effect of Maca powder on the anti-fatigue of mice and its mechanism," Journal of Hygiene Research, vol. 42, no. 6, pp. 1046-1104, 2013 (Chinese).

[34] S. Gao, Y. Tong, X. Y. Xiong, Y. Zhang, and S. P. Wu, "Experimentally comparative study of maca and americam ginseng for relieving physical fatigue," Laboratory animal science and management, vol. 23, no. 4, pp. 4-6, 2006 (Chinese).

[35] L. Wang, H.-L. Zhang, R. Lu et al., “The decapeptide CMS001 enhances swimming endurance in mice," Peptides, vol. 29, no. 7, pp. 1176-1182, 2008.

[36] J. Liu, C. Du, Y. Wang, and Z. Yu, "Anti-fatigue activities of polysaccharides extracted from Hericium erinaceus," Experimental and Therapeutic Medicine, vol. 9, no. 2, pp. 483-487, 2015. 

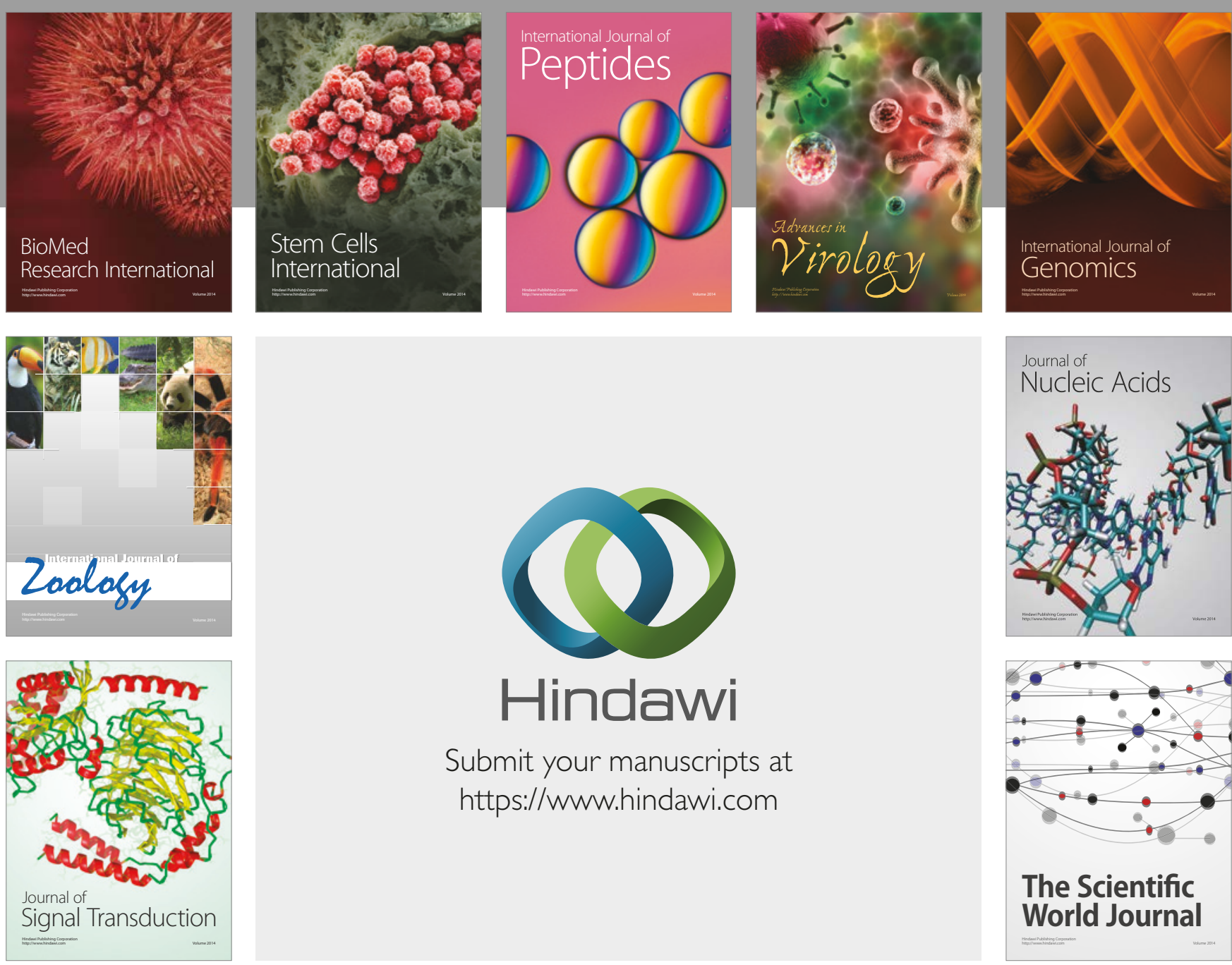

Submit your manuscripts at

https://www.hindawi.com
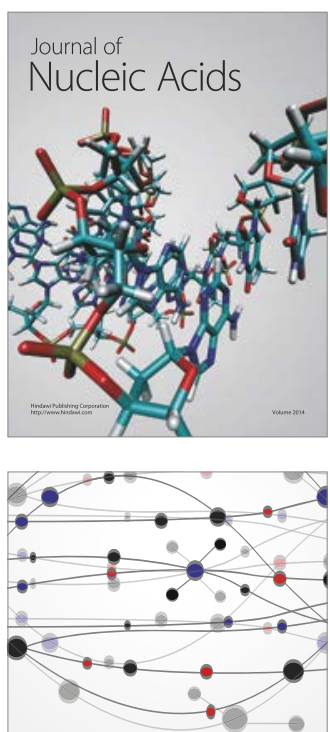

The Scientific World Journal

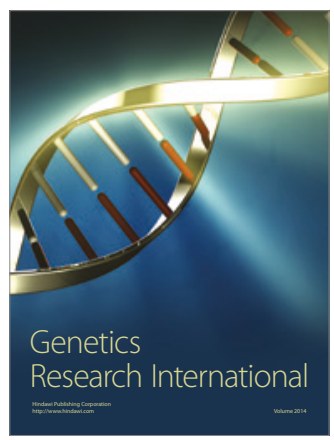

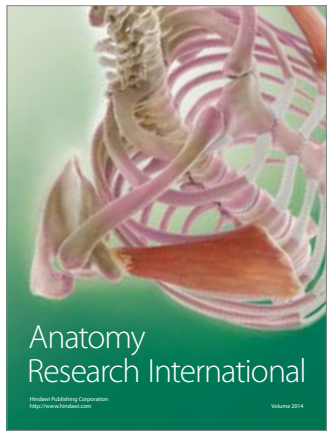

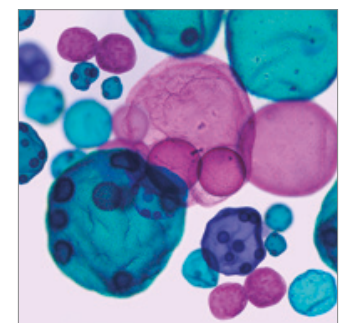

International Journal of Microbiology
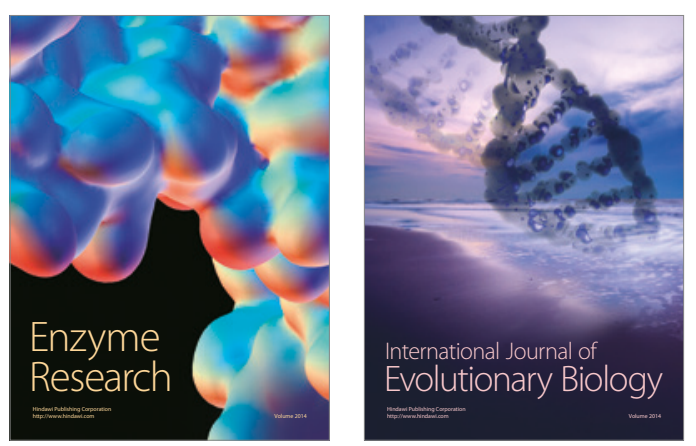
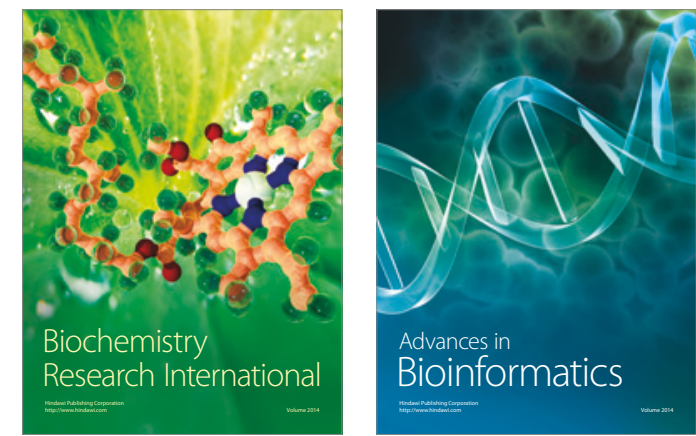

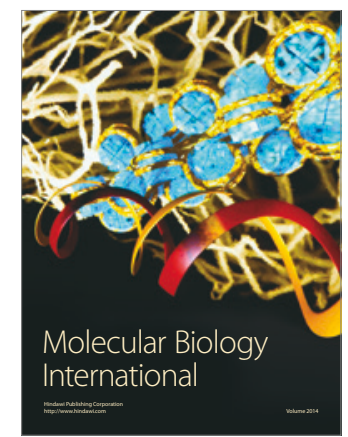

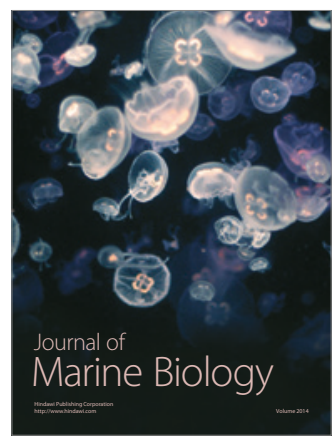

